\title{
The Impact of Carbon Source, Explants and Growth Regulators on Callogenesis and Organogenesis of Artemisia annua
}

\author{
Bita GHASSEMI*, Fatemeh DEHGHAN NAYERI, Ramin HOSSEINI
}

Imam Khomeini International University, Faculty of Engineering and Technology, Qazvin, Iran; bita.ghassemi86@gmail.com ("corresponding author)

\begin{abstract}
Artemisinin, a sesquiterpene lactone isolated from Artemisia annua L. plant is known for its antimalarial activity. The low content of artemisinin has stimulated researchers to enhance its production through biotechnological approaches such as tissue culture. The present study was initiated to study the effect of some important factors alone and in combination, on the callogenesis and organogenesis of Artemisia annua. The type of carbon source had a significant effect on NAA efficiency to callogenesis of $A$. annua, whereas the best callogenesis of $A$. absinthium was observed at $2 \mathrm{mg} / \mathrm{L} \mathrm{BAP}+30 \mathrm{~g} / \mathrm{L}$ sucrose and in the absence of NAA, with root explants. Presence of BAP also had an important effect on callogenesis, especially in high concentrations. A suitable suspension culture was obtained in the MS basal medium containing $0.5 \mathrm{mg} / \mathrm{L}$ NAA and BAP, with $30 \mathrm{~g} / \mathrm{L}$ glucose. Artemisinin was naturally production was at least $0.03 \mathrm{mg} / \mathrm{g}$ (w.dt) at the first day and peaked on the $16^{\text {th }}$ day with $0.31 \mathrm{mg} / \mathrm{g}(\mathrm{w} . \mathrm{dt})$ in the cell culture of $A$. annua. The maximum number of shoots $(2.167 \pm 1.484)$ was induced at $0.5 \mathrm{mg} / \mathrm{L} \mathrm{BAP}+0.1 \mathrm{mg} / \mathrm{L} \mathrm{NAA}+$ glucose $(30 \mathrm{~g} / \mathrm{L})$ with leaf explants. However, treatments containing glucose did not show a good shoot induction. Longer shoots were induced in the medium containing either $0.5 \mathrm{mg} / \mathrm{l} \mathrm{NAA}+0.5 \mathrm{mg} / \mathrm{l} \mathrm{BAP}$ + sucrose with leaf explants $(1.493 \mathrm{~cm} \pm 0.342)$ or $0.5 \mathrm{mg} / \mathrm{l} \mathrm{NAA}+$ sucrose with stem explants $(0.697 \mathrm{~cm} \pm 0.930)$. Medium containing 0.5 or $2 \mathrm{mg} / \mathrm{lNAA}$ and sucrose (without BAP) induced more roots though.
\end{abstract}

Keywords: humic acid, root yield, sucrose, sugar beet

\section{Introduction}

Artemisia annua L. is an annual plant from the Asteraceae family, commonly known as sweet wormwood, containing a bioactive compound called artemisinin. This natural product is a sesquiterpene lactone with an endoperoxide bridge which was isolated from $A$. annua by Chinese scientists for the first time, while seeking an effective drug to cure malaria (Klayman, 1985). Currently, artemisinin is the only commercially available antimalarial drug that is effective against chloroquine, mefloquine and primaquine (De Ridder et al., 2008) resistant strains of Plasmodium (the human malaria parasite) (Klayman, 1985) and characterized by rapid therapeutic action and low toxicity levels (De Ridder et al., 2008; Klayman, 1985; Snow et al., 2005). Artemisinin inactivates or kills off Plasmodium spp. gametocytes by the inhibition of the sarco-endoplasmic reticulum $\mathrm{Ca}^{2+}$ ATPase after activation by iron ions (EcksteinLudwig et al., 2003). In addition, artemisinin is an effective drug against a wide variety of cancers such as human leukemia, breast cancer, colon cancer and small-cell lung carcinomas (Lei et al., 2011), while has also antischistosomal activity (Utzinger $e t$ al., 2007).

A. annua has been introduced as the only commercial source of artemisinin. However, natural plants have a low content of artemisinin (0.01- 0.8\% DW) in leaves and flowers. Moreover, chemical synthesis of artemisinin is not sufficiently economical as it is exceedingly costly. Therefore, these have limited its commercialization and triggered more efforts to increase artemisinin production by other methods (Van Agtmael et al., 1999). The complex artemisinin biosynthetic pathway has prevented it from being produced by organic synthesis. The production of the sesqueterpenes by tissue culture technique has become a viable possibility (Kim et al., 1992). The optimization of culture conditions led to 10-20 folds increase in metabolites production (Deus-Neumann and Zenk,1984). Now days, in vitro techniques have been considered, as they are powerful tools for the conservation of germplasm and the multiplication of many extinct plant species (Murch et al., 2000). Genetic improvement is another approach to increase plant yield capacity to obtain higher production (Sujatha and Kumari, 2007). Prior researches have been done to explore the effect of various factors on callus induction and organogenesis of some species of Artemisia such as A. annua (Paniego and Giulietti, 1994; Ganesan and Paulsamy, 2011a), A. absinthium (Nin et al., 1996; Zia et al., 2007; Zia et al., 2007), A. vulgaris (Borzabad et al. (2010a); Borzabad et al., 2010b), A. nilagrica (Ganesan and Paulsamy, 2011b), A. scorpia (Aslam et al., 2006) etc.

The object of the current study was to study the important factors affecting callogenesis and organogenesis of $A$. annua and to establish an enriched cell suspension culture. Various explants (leaf, shoot and root), carbon source (sucrose and glucose) and different concentrations of NAA and BAP were used. Each factor was studied singly and in combination with others. To the 
476

best of our knowledge, this is the first work that investigated the effects of all these important factors on callogenesis and organogenesis of $A$. annua. It was also established a suspension culture of $A$. annua, as a suitable source for elicitation and transformation purposes.

\section{Materials and Methods}

The seeds of $A$. annua were donated by the Forest, Rangeland and Watershed Organization of Iran. Seeds were surface sterilized with $96 \%(\mathrm{v} / \mathrm{v})$ ethanol for 3 seconds and $0.1 \%(\mathrm{w} / \mathrm{v}) \mathrm{HgCl}_{2}$ for 5 minutes followed by 3 rinses with autoclaved distilled water. After surface sterilization, seeds were cultured on the solid MS medium (Murashige and Skoog, 1962 ) containing $30 \mathrm{~g} / \mathrm{L}$ sucrose, $8 \mathrm{~g} / \mathrm{L}$ agar and incubated in a growth chamber at $25 \pm 2{ }^{\circ} \mathrm{C}$ with a $16 \mathrm{~h}$ photoperiod $(3,000$ Lux). Explants (leaf, shoot and root) were detached from 1-2month old in vitro grown plantlets and cultured on the MS basal medium supplemented with sucrose or glucose $(30 \mathrm{~g} / \mathrm{l}), 8$ $\mathrm{g} / \mathrm{L}$ agar, BAP $(0,0.5$ and $2.0 \mathrm{mg} / \mathrm{l})$ and NAA $(0,0.1,0.5$ and $2.0 \mathrm{mg} / \mathrm{l})$. The $\mathrm{pH}$ of the culture medium was adjusted to 5.8 before autoclaving at $120^{\circ} \mathrm{C}$ for 20 minutes. The cultures were kept in dark at $25 \pm 2{ }^{\circ} \mathrm{C}$. Samples were subcultured every 2-3 weeks. The callus growth rate was recorded based on the difference in callus fresh weight between the first and second subcultures. After 3 subcultures, friable white leaf-derived calli obtained from $0.5 \mathrm{mg} / \mathrm{L} \mathrm{NAA}, 0.5 \mathrm{mg} / \mathrm{L} \mathrm{BAP}$ and $30 \mathrm{~g} / \mathrm{L}$ sucrose were used for the establishment of a homogenous suspension culture. One gram of selected white friable callus was excised and carefully transferred into $500 \mathrm{ml}$ narrownecked Erlenmeyer flasks containing $100 \mathrm{ml}$ of liquid MS medium supplemented with $0.1 \mathrm{mg} / \mathrm{L} \mathrm{NAA}+0.1 \mathrm{mg} / \mathrm{L}$ Kin, $0.5 \mathrm{mg} / \mathrm{L} \mathrm{NAA}+0.5 \mathrm{mg} / \mathrm{L} \mathrm{BAP}$ or $0.5 \mathrm{mg} / \mathrm{l} \mathrm{NAA}+0.05$ $\mathrm{mg} / \mathrm{l} \mathrm{Kin}$ and sucrose or glucose. The flasks were shaken at 110 rpm on a gyratory shaker and incubated at $25 \pm 2{ }^{\circ} \mathrm{C}$ in dark with a $16 \mathrm{~h}$ photoperiod. For growth analysis, samples were taken on the first day after sub-culturing at $72 \mathrm{~h}$ intervals until the $30^{\text {th }}$ day of culturing. Cultures were maintained routinely by transferring $10 \mathrm{ml}$ of the culture into $250 \mathrm{ml}$ narrow-necked Erlenmeyer flasks containing $100 \mathrm{ml}$ of fresh MS medium every 2 weeks. Viability was measured by 2,3,5-triphenyl tetrazolium (TTC) test, as described by Poobathy et al. (2012). Artemisinin was measured by HPLC with the determination of its derivative $\left(\mathrm{Q}_{260}\right)$ according to Smith et al. (1997). It was carried out by an HPLC instrument (Knauer, Germany) with the K-1001 pump, C-8 column $(0.46 \times 25 \mathrm{~cm}-5 \mu \mathrm{m}$ size $)$, equipped with a UV-Vis detector (model K-2501). The mobile phase used was $0.1 \%$ acetonitrile/acetic acid $(70: 30 \mathrm{v} / \mathrm{v})$. Flow rate was maintained at $0.2 \mathrm{ml} / \mathrm{min}$, injection volume was $50 \mu \mathrm{l}$, run time was $10 \mathrm{~min}$, and the detector wavelength was set at $260 \mathrm{~nm}$.

In this experiment completely randomized design (CRD) in three replications was used. Data were subjected to the analysis of variance (ANOVA) using statistical software MSTAT-C. Duncan's multiple range test at the $1 \%$ level was used to classify treatments. Student's test was used to compare the treatments. A p value of $<0.05$ was considered significant.

\section{Results and Discussion}

\section{Callusinduction}

Callus induction in the medium containing sucrose initiated at the first week and growth was fast, especially after the third subculture. However, in the medium containing glucose, callus induction started at $15-20^{\text {th }}$ day with a low growth rate and it significantly decreased after the $3-4^{\text {th }}$ subculture. Different callus types and colors were observed from various explants (Table 1, Figs. 1 and 2). Callogenic response from all explants started at the margins or from the cut edges (Fig. 4). In comparison to leaf and stem, root-derived calli turned brown quickly, which was possibly associated with the presence of a high level of phenolic compounds (Fig. 6).

Most of the induced calli were friable and suitable to produce suspension culture, but it strongly depended on the time of subculturing as they turned brown after 3 weeks. The rate of callogenesis was proportional to the age of explants. Explants derived from young seedlings produced the fastest growing calli.

Nin et al. (1996) reported that in A. absinthium among different growth regulators, the best callogenesis response was observed in a medium containing NAA and BAP. In the hereby study callogenesis occurred in the majority of treatments (Table 1), but the best results were obtained with $0.1 \mathrm{mg} / \mathrm{l} \mathrm{NAA}+2 \mathrm{mg} / \mathrm{l} \mathrm{BAP}+30 \mathrm{~g} / \mathrm{L}$ sucrose, using leaf and shoot explants. Root explants were also responsive to the treatment containing $0.5 \mathrm{mg} / \mathrm{l} \mathrm{NAA}, 2 \mathrm{mg} / \mathrm{l} \mathrm{BAP}$ and $30 \mathrm{~g} / \mathrm{L}$ sucrose. After 5 months of continuous subculturing, leaf explants had a better growth rate than root and shoot explants. In addition, no calli were induced in the control (without hormones) and in the leaf explants cultured in the media supplemented with 0.5 or $2 \mathrm{mg} / \mathrm{l} \mathrm{BAP}$ and $30 \mathrm{~g} / \mathrm{L}$ glucose. Nin et al. (1996) also reported no calli in the basal MS medium, but based on Zia et al. (2007) the highest frequency of callus induction $(75 \%$ and $50 \%$ from leaf and shoot explants, respectively) in $A$. absinthium was obtained on a medium lacking hormones. The highest value $(0.729 \mathrm{~g} \pm 0.070)$ of callus fresh weight was obtained using sucrose in comparison with glucose $(0.466 \mathrm{~g} \pm 0.44)$. In this study it was found that leaves and roots were the best explant types for callus induction (Fig. 7 , Table 4). The best callogenic response $(1.562 \mathrm{~g} \pm 0.672)$ was observed with the leaf explants cultured on the medium supplemented with $30 \mathrm{~g} / \mathrm{L}$ sucrose. Keng et al. (2007) also reported that the best friable calli were obtained using leaf explants.

In the interaction between NAA and the type of carbon source (sucrose and glucose), fast callus growth (1.079 $\mathrm{g} \pm$ 0.292 ) was recorded in the medium containing $30 \mathrm{~g} / \mathrm{L}$ sucrose and $0.1 \mathrm{mg} / \mathrm{L}$ NAA (Table 9), whereas less amount of callus $(0.87 \mathrm{~g} \pm 0.292)$ was produced in the cultures supplied with glucose and $0.1 \mathrm{mg} / \mathrm{L}$ NAA. No difference of callus weight was observed in various concentrations of NAA (Table 8). It was observed that for callus induction the type of carbon source had a significant effect on NAA function, since no difference on callus weight was obtained in interaction of NAA $\times$ BAP, whereas in the interaction of NAA $\times$ BAP $\times$ carbon (Table 10) the calli obtained in the treatment containing $0.1 \mathrm{NAA}+2$ $\mathrm{mg} / \mathrm{L} \mathrm{BAP}+$ sucrose had the maximum weight $(2.886 \mathrm{~g} \pm$ $0.2)$. In the interaction between NAA, carbon and explants (Table 12), the highest weight was obtained with root explants in $0.5 \mathrm{mg} / \mathrm{L}$ NAA and sucrose $(2.14 \mathrm{~g} \pm 0.8)$. In investigating the effect of NAA and explants (Table 6), the best result was obtained with leaf explants in $2 \mathrm{mg} / \mathrm{L}$ NAA $(1.676 \mathrm{~g} \pm 0.4)$ and root explants in $0.5 \mathrm{mg} / \mathrm{LNAA}(1.857 \mathrm{~g} \pm 0.6)$.

According to the current findings, the highest and lowest fresh weights of calli were obtained in the medium containing 
Table 1. The callogenesis response of $A$. annua different explants to various concentrations and combinations of growth regulators and carbon sources

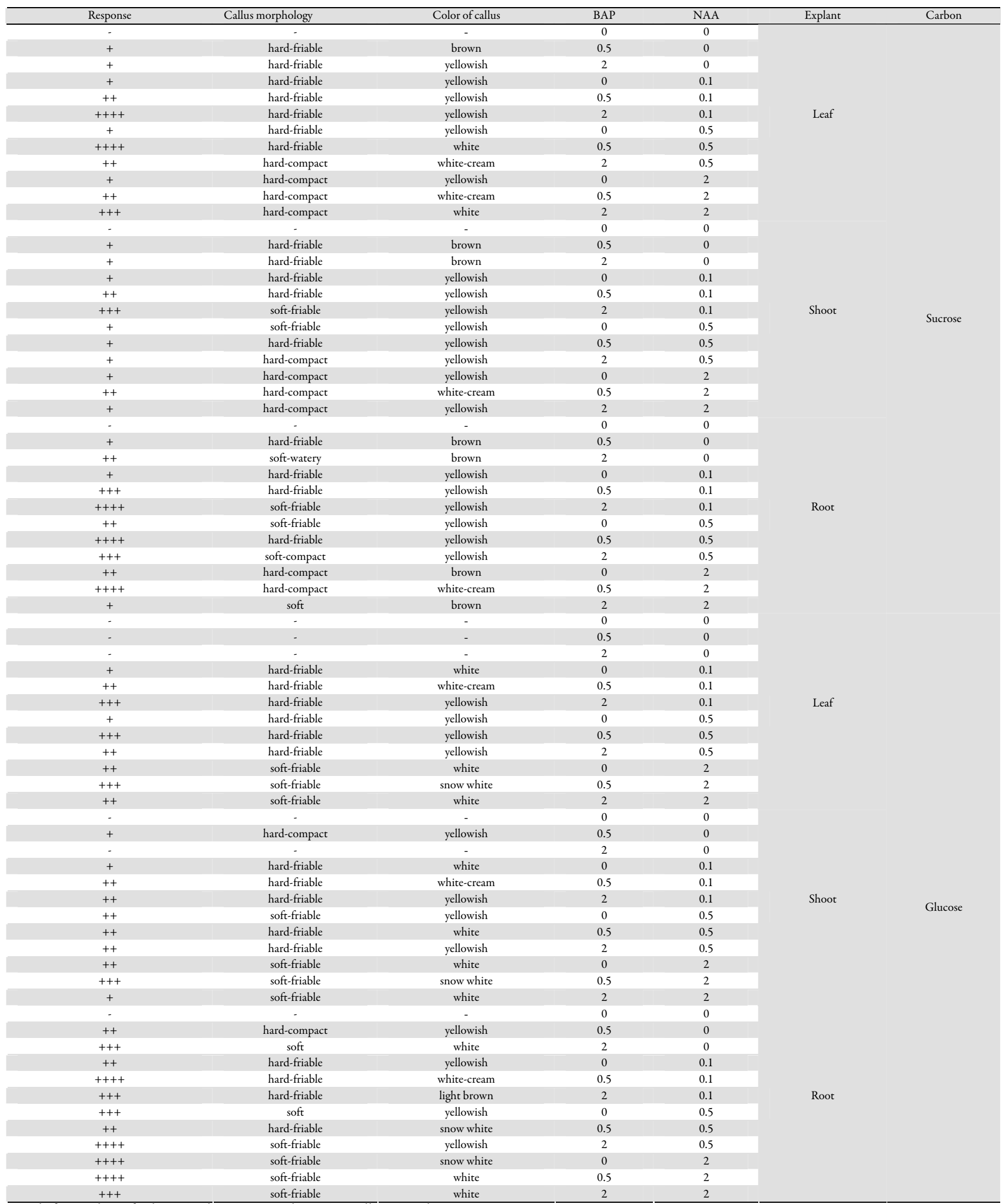

Rated after 60 days of culture: '+': low, '++': good, '+++': excellent, '-': nil

$30 \mathrm{~g} / \mathrm{L}$ sucrose and $2 \mathrm{mg} / \mathrm{L}$ BAP and in the medium containing glucose or sucrose without BAP, respectively (Table 5). It was proposed that BAP has an important effect on callogenesis. The best result of callogenesis was achieved on the MS medium supplemented with $0.1 \mathrm{mg} / \mathrm{lNAA}$ and 2 $\mathrm{mg} / \mathrm{l} \mathrm{BAP}$, while the explants on the medium containing 0.1 $\mathrm{mg} / \mathrm{l}$ NAA (without BAP) or the medium lacking hormones produced the lowest weight of callus (Table 2, Fig. 8).

According to the interaction of the four important factors in the experiment (NAA and BAP, carbon source and explants), the calli obtained from the leaf, root and shoot explants on the media containing $0.1 \mathrm{mg} / \mathrm{LNAA}$ and $2 \mathrm{mg} / \mathrm{L} \mathrm{BAP}$ with sucrose 
478

Table 2. The effect of growth regulators on callus, shoot and root induction of $A$. annua on MS medium

\begin{tabular}{|c|c|c|c|c|c|}
\hline Root length & No. root & No. stem & Fresh weight of callus (g) & BAP & NAA \\
\hline $0.989 \pm 0.507 \mathrm{~b}$ & $0.973 \pm 0.437 \mathrm{c}$ & $0.710 \pm 0.00 \mathrm{~b}$ & $0.741 \pm 0.056 \mathrm{~g}$ & 0 & 0 \\
\hline $0.710 \pm 0.00 \mathrm{c}$ & $0.710 \pm 0.00 \mathrm{~d}$ & $0.006 \pm 0.570 \mathrm{ab}$ & $0.991 \pm 0.441$ ef & 0.5 & 0 \\
\hline $0.710 \pm 0.00 \mathrm{c}$ & $0.710 \pm 0.00 \mathrm{~d}$ & $1.211 \pm 0.079 \mathrm{a}$ & $1.059 \pm 0.386 \mathrm{def}$ & 2 & 0 \\
\hline $1.00 \pm 0.640 \mathrm{~b}$ & $0.890 \pm 0.367 \mathrm{~cd}$ & $0.807 \pm 0.338 b$ & $0.915 \pm 0.216 \mathrm{fg}$ & 0 & 0.1 \\
\hline $0.710 \pm 0.00 \mathrm{c}$ & $0.710 \pm 0.00 \mathrm{~d}$ & $1.288 \pm 0.747 \mathrm{a}$ & $1.201 \pm 0.371 \mathrm{~cd}$ & 0.5 & 0.1 \\
\hline $0.710 \pm 0.00 \mathrm{c}$ & $0.710 \pm 0.00 \mathrm{~d}$ & $1.242 \pm 0.990 \mathrm{a}$ & $2.127 \pm 0.855 \mathrm{a}$ & 2 & 0.1 \\
\hline $1.260 \pm 0.548 \mathrm{a}$ & $1.827 \pm 1.090 \mathrm{~b}$ & $0.790 \pm 0.278 \mathrm{~b}$ & $1.156 \pm 0.199 \mathrm{cde}$ & 0 & 0.5 \\
\hline $0.710 \pm 0.00 \mathrm{c}$ & $0.710 \pm 0.00 \mathrm{~d}$ & $1.203 \pm 0.817 \mathrm{a}$ & $1.733 \pm 0.573 b$ & 0.5 & 0.5 \\
\hline $0.710 \pm 0.00 \mathrm{c}$ & $0.710 \pm 0.00 \mathrm{~d}$ & $0.796 \pm 0.368 \mathrm{~b}$ & $1.645 \pm 0.733 b$ & 2 & 0.5 \\
\hline $1.185 \pm 0.559 \mathrm{a}$ & $2.266 \pm 1.431 \mathrm{a}$ & $0.710 \pm 0.00 \mathrm{~b}$ & $1.294 \pm 0.254 c$ & 0 & 2 \\
\hline $0.710 \pm 0.00 \mathrm{c}$ & $0.738 \pm 0.122 \mathrm{~cd}$ & $0.824 \pm 0.378 \mathrm{~b}$ & $1.767 \pm 0.403 \mathrm{~b}$ & 0.5 & 2 \\
\hline $0.710 \pm 0.00 \mathrm{c}$ & $0.710 \pm 0.00 \mathrm{~d}$ & $0.710 \pm 0.00 \mathrm{~b}$ & $1.219 \pm 0.510 \mathrm{~cd}$ & 2 & 2 \\
\hline
\end{tabular}

Table 3. The effect of BAP on callus weight, shoot and root induction

\begin{tabular}{|c|c|c|c|c|c|}
\hline Root length & No. root & Stem length & No. stem & Callus weight & BAP \\
\hline $1.109 \pm 0.566 \mathrm{a}$ & $1.489 \pm 1.096 \mathrm{a}$ & $0.762 \pm 0.245 \mathrm{a}$ & $0.754 \pm 0.219 b$ & $1.026 \pm 0.28 \mathrm{~b}$ & 0 \\
\hline $0.7100 \pm 0.00 \mathrm{~b}$ & $0.717 \pm 0.061 b$ & $0.870 \pm 0.27 b$ & $1.078 \pm 0.662 \mathrm{a}$ & $1.423 \pm 0.577 \mathrm{a}$ & 0.5 \\
\hline $0.7100 \pm 0.00 \mathrm{~b}$ & $0.7100 \pm 0.00 \mathrm{~b}$ & $0.756 \pm 0.133 c$ & $0.989 \pm 0.744 a$ & $1.512 \pm 0.780 \mathrm{a}$ & 2 \\
\hline
\end{tabular}

Table 4. The effect of explants on callus, shoot and root induction of $A$. annua on MS medium

\begin{tabular}{|c|c|c|c|c|c|}
\hline Root length & No. root & Shoot length & No. shoot & Callus weight & Explant \\
\hline $0.976 \pm 0.558 \mathrm{a}$ & $1.073 \mathrm{a} \pm 1.20$ & $0.254 \mathrm{a} \pm 0.8512$ & $1.150 \pm 0.785 \mathrm{a}$ & $1.379 \pm 0.62$ a & Leaf \\
\hline $0.8081 \pm 0.263 b$ & $0.385 \mathrm{~b} \pm 0.8599$ & $0.287 a \pm 0.8347$ & $0.061 \mathrm{a} \pm 0.618$ & $1.174 \pm 0.57 \quad b$ & Stem \\
\hline $0.138 \mathrm{~b} \pm 0.7446$ & $0.479 \mathrm{~b} \pm 0.850$ & $0.000 \mathrm{~b} \pm 0.710$ & $0.7100 \mathrm{~b} \pm 0.000$ & $1.409 \pm 0.62 \mathrm{a}$ & Root \\
\hline
\end{tabular}

Table 5. The interaction between carbon source and BAP on callus, shoot and root induction of $A$. annua on MS medium

\begin{tabular}{|c|c|c|c|c|c|}
\hline Root length & No. root & No. shoot & Callus weight & BAP & Carbon \\
\hline $1.199 \pm 0.659 \mathrm{a}$ & $1.701 \pm 1.196 \mathrm{a}$ & $0.7503 \pm 0.198 b$ & $1.037 \pm 0.299 \mathrm{~d}$ & 0 & \multirow{3}{*}{ Sucrose } \\
\hline $0.7100 \pm 0.0 c$ & $0.710 \pm 0.0 \mathrm{c}$ & $1.259 \pm 0.816 a$ & $1.37 \pm 0.528 \mathrm{bc}$ & 0.5 & \\
\hline $0.7100 \pm 0.0 \mathrm{c}$ & $0.710 \pm 0.0 c$ & $1.212 \pm 0.975 \mathrm{a}$ & $1.746 \pm 0.989 \mathrm{a}$ & 2 & \\
\hline $1.018 \pm 0.445 b$ & $1.27 \pm 0.956 \mathrm{~b}$ & $0.7586 \pm 0.240 b$ & $1.016 \pm 0.281 \mathrm{~d}$ & 0 & \multirow{3}{*}{ Glucose } \\
\hline $0.7100 \pm 0.0 c$ & $0.724 \pm 0.086 c$ & $0.8608 \pm 0.356 \mathrm{~b}$ & $1.468 \pm 0.590 \mathrm{~b}$ & 0.5 & \\
\hline $0.7100 \pm 0.0 c$ & $0.7100 \pm 0.0 \mathrm{c}$ & $0.7672 \pm 0.270 b$ & $1.279 \pm 0.362 \mathrm{c}$ & 2 & \\
\hline
\end{tabular}

Table 6. The interaction between NAA and explants on callus, shoot and root induction of $A$. annua on MS medium

\begin{tabular}{|c|c|c|c|c|c|}
\hline No. root & Shoot length & No. shoot & Callus weight & NAA & Explants \\
\hline $0.8706 \pm 0.402 \mathrm{~cd}$ & $0.8406 \pm 0.194 \mathrm{bc}$ & $1.261 \pm 0.852 \mathrm{ab}$ & $0.975 \pm 0.446 \mathrm{de}$ & 0 & \multirow{5}{*}{ Leaf } \\
\hline $0.8511 \pm 0.344 \mathrm{~cd}$ & $0.9739 \pm 0.272 \mathrm{a}$ & $1.527 \pm 0.009 \mathrm{a}$ & $1.393 \pm 0.829 b c$ & 0.1 & \\
\hline $1.307 \pm 1.152 b$ & $0.8428 \pm 0.323 b c$ & $1.016 \pm 0.617 \mathrm{bcde}$ & $1.471 \pm 0.479 b$ & 0.5 & \\
\hline $1.797 \pm 1.602 \mathrm{a}$ & $0.7478 \pm 0.160 \mathrm{~cd}$ & $0.7961 \pm 0.365 \mathrm{cde}$ & $1.676 \pm 0.465 a$ & 2 & \\
\hline $0.8133 \pm 0.312 \mathrm{~cd}$ & $0.7633 \pm 0.156 \mathrm{~cd}$ & $0.9456 \pm 0.727 \mathrm{cde}$ & $0.798 \pm 0.129 \mathrm{e}$ & 0 & \\
\hline $0.7489 \pm 0.166 \mathrm{~cd}$ & $0.8994 \pm 0.352 \mathrm{ab}$ & $1.099 \pm 0.655 b c$ & $1.448 \pm 0.785 b$ & 0.1 & \multirow{3}{*}{ Stem } \\
\hline $0.9711 \pm 0.548 \mathrm{~cd}$ & $0.9217 \pm 0.391 \mathrm{ab}$ & $1.064 \pm 0.734 \mathrm{bcd}$ & $1.206 \pm 0.491 \mathrm{c}$ & 0.5 & \\
\hline $0.9061 \pm 0.404 \mathrm{~cd}$ & $0.7544 \pm 0.136 \mathrm{~cd}$ & $0.7383 \pm 0.122 \mathrm{de}$ & $1.243 \pm 0.499 c$ & 2 & \\
\hline $0.7100 \pm 0.000 \mathrm{~d}$ & $0.7100 \pm 0.000 \mathrm{~d}$ & $0.7100 \pm 0.000 \mathrm{e}$ & $1.017 \pm 0.404 \mathrm{~d}$ & 0 & \multirow{4}{*}{ Root } \\
\hline $0.7100 \pm 0.000 \mathrm{~d}$ & $0.7100 \pm 0.000 \mathrm{~d}$ & $0.7100 \pm 0.000 \mathrm{e}$ & $1.402 \pm 0.739 b c$ & 0.1 & \\
\hline $0.9689 \pm 0.603 \mathrm{~cd}$ & $0.7100 \pm 0.000 \mathrm{~d}$ & $0.7100 \pm 0.000 \mathrm{e}$ & $1.857 \pm 0.675 \mathrm{a}$ & 0.5 & \\
\hline $1.011 \pm 0.714 c$ & $0.7100 \pm 0.000 \mathrm{~d}$ & $0.7100 \pm 0.000 \mathrm{e}$ & $1.361 \pm 0.323 b c$ & 2 & \\
\hline
\end{tabular}

Table 7. The effect of BAP and explants on callus, shoot and root induction of $A$. annua on MS medium

\begin{tabular}{|c|c|c|c|c|c|c|}
\hline Root length & No. root & Shoot length & No. shoot & Callus weight & BAP & Explant \\
\hline $1.508 \pm 0.718 \mathrm{a}$ & $2.199 \pm 1.41 \mathrm{a}$ & $0.7271 \pm 0.083 \mathrm{~cd}$ & $0.7242 \pm 0.069 \mathrm{c}$ & $1.080 \pm 0.334 \mathrm{e}$ & 0 & \multirow{3}{*}{ Leaf } \\
\hline- & - & $1.0090 \pm 0.338 \mathrm{a}$ & $1.408 \pm 0.781 \mathrm{a}$ & $1.5130 .633 \pm b$ & 0.5 & \\
\hline - & - & $0.8179 \pm 0.184 \mathrm{bcd}$ & $1.318 \pm 1.000 \mathrm{a}$ & $1.543 \pm 0.732 \mathrm{~b}$ & 2 & \\
\hline $1.004 \pm 0.392 b$ & $1.138 \pm 0.569 b$ & $0.8592 \pm 0.406 \mathrm{bc}$ & $0.829 \pm 0.366 b c$ & $0.966 \pm 0.205 \mathrm{e}$ & 0 & \multirow{3}{*}{ Stem } \\
\hline $0.0 \pm 0.0 \mathrm{c}$ & $0.7312 \pm 0.105 c$ & $0.8983 \pm 0.251 \mathrm{ab}$ & $1.115 \pm 0.698 \mathrm{ab}$ & $1.303 \pm 0.528 \mathrm{~cd}$ & 0.5 & \\
\hline - & - & $0.7467 \pm 0.119 \mathrm{~cd}$ & $0.9412 \pm 0.718 b c$ & $1.252 \pm 0.784 \mathrm{~d}$ & 2 & \\
\hline $0.8137 \pm 0.226 c$ & $1.130 \pm 0.765 b$ & - & - & $1.033 \pm 0.310 \mathrm{e}$ & 0 & \multirow{3}{*}{ Root } \\
\hline- & - & - & - & $1.452 \pm 0.507 \mathrm{bc}$ & 0.5 & \\
\hline- & - & - & - & $1.742 \pm 0.77 \mathrm{a}$ & 2 & \\
\hline
\end{tabular}

Table 8. The effect of NAA on callus, shoot and root induction of $A$. annua on MS medium

\begin{tabular}{lllll}
\hline No. root & Shoot length & No. shoot & Callus weight & NAA \\
\hline $0.7980 \pm 0.296 \mathrm{c}$ & $0.7713 \pm 0.15 \mathrm{lab}$ & $0.9722 \pm 0.67 \mathrm{ab}$ & $0.930 \pm 0.361 \mathrm{~b}$ & 0 \\
$0.770 \pm 0.225 \mathrm{c}$ & $0.276 \pm 0.861 \mathrm{a}$ & $1.112 \pm 0.760 \mathrm{a}$ & $1.414 \pm 0.771 \mathrm{a}$ & 0.1 \\
$1.082 \pm 0.815 \mathrm{~b}$ & $0.8248 \pm 0.301 \mathrm{ab}$ & $0.9300 \pm 0.566 \mathrm{ab}$ & $1.511 \pm 0.613 \mathrm{a}$ & 0.5 \\
$1.238 \pm 1.095 \mathrm{a}$ & $0.7374 \pm 0.12 \mathrm{~b}$ & $0.7481 \pm 0.221 \mathrm{~b}$ & $1.426 \pm 0.465 \mathrm{a}$ \\
\hline
\end{tabular}


Table 9. The effect of NAA and carbon sources on callus, shoot and root induction of $A$. anmua on MS medium

\begin{tabular}{lllll}
\hline Root length & No. root & Shoot length & Callus weight & Carbon \\
\hline- & - & $0.8137 \pm 0.182 \mathrm{ab}$ & $0.984 \pm 0.358 \mathrm{de}$ & \\
$0.9033 \pm 0.536 \mathrm{ab}$ & $0.8300 \pm 0.309 \mathrm{~b}$ & $0.8493 \pm 0.240 \mathrm{a}$ & $1.709 \pm 0.961 \mathrm{a}$ & \\
$0.9822 \pm 0.509 \mathrm{a}$ & $1.298 \pm 0.039 \mathrm{a}$ & $0.9100 \pm 0.396 \mathrm{a}$ & $1.482 \pm 0.771 \mathrm{bc}$ & \\
$0.8967 \pm 0.468 \mathrm{ab}$ & $1.323 \pm 0.160 \mathrm{a}$ & $0.7459 \pm 0.140 \mathrm{~b}$ & $1.372 \pm 0.483 \mathrm{c}$ & 0.1 \\
$0.8963 \pm 0.431 \mathrm{ab}$ & $0.8859 \pm 0.403 \mathrm{~b}$ & $0.7289 \pm 0.099 \mathrm{~b}$ & $0.875 \pm 0.362 \mathrm{e}$ & 2 \\
- & - & $0.8730 \pm 0.312 \mathrm{a}$ & $1.120 \pm 0.292 \mathrm{~d}$ & 0 \\
$0.8044 \pm 0.247 \mathrm{bc}$ & $0.8670 \pm 0.422 \mathrm{~b}$ & $0.7396 \pm 0.112 \mathrm{~b}$ & $1.540 \pm 0.413 \mathrm{~b}$ & 0.1 \\
$0.8400 \pm 0.298 \mathrm{abc}$ & $1.153 \pm 0.041 \mathrm{a}$ & $0.7289 \pm 0.099 \mathrm{~b}$ & $1.481 \pm 0.449 \mathrm{bc}$ & 0.5 \\
\hline
\end{tabular}

Table 10. The effect of interaction between growth regulators and carbon on callus, shoot and root induction of $A$. anmua on MS medium

\begin{tabular}{|c|c|c|c|c|c|c|c|}
\hline Root length & No.root & Shootlength & No.shoot & Callusweight & BAP & NAA & Carbon \\
\hline- & - & - & - & $0.763 \pm 0.073 j$ & 0 & 0 & \multirow{12}{*}{ Sucrose } \\
\hline- & - & $0.8878 \pm 0.231 \mathrm{abc}$ & $1.282 \pm 0.711 \mathrm{abcd}$ & $1.190 \pm 0.555 \mathrm{defg}$ & 0.5 & 0 & \\
\hline $0.01 \pm 0.0 \mathrm{~d}$ & $0.71 \pm 0.0 \mathrm{e}$ & $0.8433 \pm 0.185 b c$ & $1.539 \pm 1.235 \mathrm{ab}$ & $1.001 \pm 0.028$ ghij & 2 & 0 & \\
\hline $1.290 \pm 0.826 \mathrm{ab}$ & $1.070 \pm 0.461 \mathrm{~cd}$ & - & - & $0.99 \pm 50.270 \mathrm{ahij}$ & 0 & 0.1 & \\
\hline $0.01 \pm 0.0 \mathrm{~d}$ & $0.7100 \pm 0.0 \mathrm{e}$ & $0.968 \pm 0.314 \mathrm{ab}$ & $1.391 \pm 0.930 \mathrm{abc}$ & $1.244 \pm 0.438 \mathrm{defg}$ & 0.5 & 0.1 & \\
\hline- & - & $0.868 \pm 0.224 a b c$ & $1.717 \pm 1.243 \mathrm{a}$ & $2.886 \pm 0.242 \mathrm{a}$ & 2 & 0.1 & \\
\hline $1.527 \pm 0.582 \mathrm{a}$ & $2.473 \pm 1.083 a$ & $0.9711 \pm 0.525 \mathrm{ab}$ & $0.8711 \pm 0.387 \mathrm{de}$ & $1.022 \pm 0.107$ fghi & 0 & 0.5 & \\
\hline $0.71 \pm 0.0 \mathrm{~d}$ & $0.71 \pm 0.000 \mathrm{e}$ & $1.044 \pm 0.406 a$ & $1.567 \pm 1.016 \mathrm{ab}$ & $1.489 \pm 0.700 \mathrm{~cd}$ & 0.5 & 0.5 & \\
\hline- & - & $0.7144 \pm 0.015 c$ & $0.8833 \pm 0.521 \mathrm{de}$ & $1.886 \pm 1.008 \mathrm{~b}$ & 2 & 0.5 & \\
\hline $1.270 \pm 0.688 \mathrm{abc}$ & $2.549 \pm 1.356 a$ & - & - & $1.318 \pm 0.291 \mathrm{cdef}$ & 0 & 2 & \\
\hline- & - & $0.8178 b \pm 0.235 c$ & $0.9389 \pm 0.524 \mathrm{cde}$ & $1.587 \pm 0.326 c$ & 0.5 & 2 & \\
\hline- & - & - & - & $1.212 \pm 0.695 \mathrm{defg}$ & 2 & 2 & \\
\hline $1.269 \pm 0.608 \mathrm{abc}$ & $1.238 \pm 0.564 c$ & - & - & $0.718 \pm 0.015 \mathrm{j}$ & 0 & 0 & \multirow{12}{*}{ Glucose } \\
\hline- & - & - & - & $0.792 \pm 0.127 \mathrm{ij}$ & 0.5 & 0 & \\
\hline - & - & $0.7667 \pm 0.172 c$ & $0.8822 \pm 0.517 \mathrm{de}$ & $1.117 \pm 0.557 \mathrm{efgh}$ & 2 & 0 & \\
\hline - & - & $0.8922 \pm 0.415 \mathrm{abc}$ & $0.9044 \pm 0.470 \mathrm{de}$ & $0.834 \pm 0.11 \mathrm{hij}$ & 0 & 0.1 & \\
\hline- & - & $0.9844 \pm 0.316 \mathrm{ab}$ & $1.181 \pm 0.545 \mathrm{bcde}$ & $1.158 \pm 0.309 \mathrm{efg}$ & 0.5 & 0.1 & \\
\hline- & - & $0.7422 \pm 0.097 \mathrm{c}$ & $0.7667 \pm 0.172 \mathrm{e}$ & $1.363 \pm 0.078 \mathrm{cdef}$ & 2 & 0.1 & \\
\hline $0.9933 \pm 0.370 c$ & $1.181 \pm 0.642 c$ & - & - & $1.240 \pm 0.13 \mathrm{defg}$ & 0 & 0.5 & \\
\hline- & - & $0.7989 \pm 0.187 \mathrm{bc}$ & $0.8389 \pm 0.295 \mathrm{de}$ & $1.977 \pm 0.269 \mathrm{~b}$ & 0.5 & 0.5 & \\
\hline- & - & - & - & $1.404 \pm 0.354 \mathrm{cde}$ & 2 & 0.5 & \\
\hline $1.001 \pm 0.417 b c$ & $1.982 \pm 1.527 \mathrm{~b}$ & - & - & $1.270 \pm 0.225 \mathrm{defg}$ & 0 & 2 & \\
\hline $0.00 \pm 0.0 \mathrm{~d}$ & $0.7667 \pm 0.172 \mathrm{de}$ & $0.7667 \pm 0.172 c$ & $0.7100 \pm 0.000 \mathrm{e}$ & $1.947 \pm 0.408 \mathrm{~b}$ & 0.5 & 2 & \\
\hline- & - & - & - & $1.226 \pm 0.266 \mathrm{defg}$ & 2 & 2 & \\
\hline
\end{tabular}

Table 11. The effect of interaction between BAP, explants and carbon on callus, shoot and root induction of $A$. annua on MS medium

\begin{tabular}{|c|c|c|c|c|c|c|c|}
\hline Root length & No. root & Shoot length & No. shoot & Callus weight & BAP & Explant & Carbon \\
\hline $1.732 \pm 0.829 a$ & $2.474 \pm 0.512 \mathrm{a}$ & - & - & $1.252 \pm 0.377 \mathrm{cde}$ & 0 & \multirow{3}{*}{ Leaf } & \multirow{9}{*}{ Sucrose } \\
\hline $0.7100 \pm 0.000 \mathrm{~d}$ & $0.710 \pm 0.000 \mathrm{e}$ & $1.210 \pm 0.326 \mathrm{a}$ & $1.932 \pm 0.724 a$ & $1.521 \pm 0.538 b$ & 0.5 & & \\
\hline- & - & $0.8833 \pm 0.198 b c$ & $1.797 \pm 1.078 \mathrm{a}$ & $1.913 \pm 0.833 \mathrm{a}$ & 2 & & \\
\hline $0.9483 \pm 0.386 c$ & $1.077 \pm 0.572 \mathrm{~d}$ & $0.9058 \pm 0.463 \mathrm{bc}$ & $0.8308 \pm 0.33 b c$ & $0.904 \pm 0.145 \mathrm{~g}$ & 0 & \multirow{3}{*}{ Shoot } & \\
\hline- & - & $0.8692 \pm 0.212 b c$ & $1.242 \pm 0.879 \mathrm{~b}$ & $1.112 \pm 0.198 \mathrm{efg}$ & 0.5 & & \\
\hline- & - & $0.7592 \pm 0.149 b c$ & $1.130 \pm 0.989 b c$ & $1.411 \pm 1.027 \mathrm{bcd}$ & 2 & & \\
\hline $0.9175 \pm 0.289 \mathrm{~cd}$ & $1.550 \pm 0.915 c$ & - & - & $0.955 \pm 0.210 \mathrm{fg}$ & 0 & \multirow{3}{*}{ Root } & \\
\hline- & - & - & - & $1.499 \pm 0.665 b c$ & 0.5 & & \\
\hline- & - & - & - & $1.914 \pm 1.069 \mathrm{a}$ & 2 & & \\
\hline $1.284 \pm 0.530 b$ & $1.924 \pm 1.322 b$ & $0.744 \pm 0.118 b c$ & $0.7383 \pm 0.098 \mathrm{c}$ & $0.909 \pm 0.908 \mathrm{~g}$ & 0 & \multirow{3}{*}{ Leaf } & \multirow{9}{*}{ Glucose } \\
\hline- & - & $0.807 \pm 0.209 b c$ & $0.884 \pm 0.38 b c$ & $1.505 \pm 0.740 \mathrm{bc}$ & 0.5 & & \\
\hline- & - & $0.752 \pm 0.149 b c$ & $0.839 \pm 0.447 b c$ & $1.173 \pm 0.239 \mathrm{def}$ & 2 & & \\
\hline $1.060 \pm 0.407 \mathrm{bc}$ & $1.199 \pm 0.584 \mathrm{~d}$ & $0.8125 \pm 0.354 b c$ & $0.8275 \pm 0.408 b c$ & $1.028 \pm 0.242 \mathrm{efg}$ & 0 & \multirow{3}{*}{ Shoot } & \\
\hline $0.71 \pm 0.0 \mathrm{~d}$ & $0.7525 \pm 0.149 \mathrm{e}$ & $0.927 \pm 0.292 b$ & $0.9883 \pm 0.458 b c$ & $1.494 \pm 0.681 b c$ & 0.5 & & \\
\hline- & - & $0.7342 \pm 0.084 b c$ & $0.7525 \pm 0.149 c$ & $1.094 \pm 0.418 \mathrm{efg}$ & 2 & & \\
\hline- & - & - & - & $1.110 \pm 0.380 \mathrm{efg}$ & 0 & \multirow{3}{*}{ Root } & \\
\hline- & - & - & - & $1.406 \pm 0.299 \mathrm{bcd}$ & 0.5 & & \\
\hline- & - & - & - & $1.569 \pm 0.208 \mathrm{~b}$ & 2 & & \\
\hline
\end{tabular}

and also the calli produced from root explants on the media containing $0.5 \mathrm{mg} / \mathrm{L}$ NAA, $2 \mathrm{mg} / \mathrm{L} \mathrm{BAP}$ and sucrose had the highest callus weight. In one hand, the shoot and rootinduced calli had a good growth rate until the second subculture, and after that (six sequential subcultures were investigated) their growth rate decreased. On the other hand, root-induced calli on the medium supplemented with $0.5 \mathrm{mg} / \mathrm{L} \mathrm{NAA}$ and $2 \mathrm{mg} / \mathrm{L}$ BAP turned brown. Moreover, according to Keng et al. (2007) the yield of artemisinin was higher in aerial plant parts. Therefore, the type of explants is important, while calli were used as the source material to establish cell suspension culture for future elicitation purpose. Based on all these facts, although the highest weight of calli was obtained with shoot and root explants, they were not useful for initiating cell suspension culture.

Finally, by considering color, appearance, texture and growth rate, a fast-growing friable callus obtained from leaf explants on the medium supplemented with $0.5 \mathrm{mg} / \mathrm{L}$ $\mathrm{NAA}+0.5 \mathrm{mg} / \mathrm{L} \mathrm{BAP}+30 \mathrm{~g} / \mathrm{L}$ sucrose was chosen for initiating cell suspension culture. 
Table 12. The effect of interaction of NAA, carbon and explant on callus and root induction of $A$. annua on MS medium

\begin{tabular}{|c|c|c|c|c|c|}
\hline Root length & No. root & Callus weight & NAA & Explant & Carbon \\
\hline $0.00 \pm 0.0 \mathrm{e}$ & $0.7100 \pm 0.000 \mathrm{~d}$ & $1.204 \pm 0.550 \mathrm{ghi}$ & 0 & \multirow{4}{*}{ Leaf } & \multirow{12}{*}{ Sucrose } \\
\hline $1.217 \pm 0.847 \mathrm{a}$ & $0.9922 \pm 0.455 \mathrm{bcd}$ & $1.769 \pm 0.983 \mathrm{bcd}$ & 0.1 & & \\
\hline $1.124 \pm 0.732 \mathrm{abc}$ & $1.672 \pm 0.512 \mathrm{a}$ & $1.431 \pm 0.497 \mathrm{efgh}$ & 0.5 & & \\
\hline $1.151 \pm 0.747 \mathrm{ab}$ & $1.818 \pm 0.676 \mathrm{a}$ & $1.843 \pm 0.314 \mathrm{~b}$ & 2 & & \\
\hline $0.0 \pm 0.0 \mathrm{e}$ & $0.7100 \pm 0.000 \mathrm{~d}$ & $0.887 \pm 0.131 \mathrm{jklm}$ & 0 & \multirow{5}{*}{ Shoot } & \\
\hline $0.7833 \pm 0.220 \mathrm{de}$ & $0.7878 \pm 0.235 \mathrm{~d}$ & $1.810 \pm 0.987 \mathrm{bc}$ & 0.1 & & \\
\hline $0.9000 \pm 0.406 \mathrm{bcde}$ & $0.99 \pm 0.577 \mathrm{bcd}$ & $0.865 \pm 0.078 \mathrm{klm}$ & 0.5 & & \\
\hline $0.7644 \pm 0.165 \mathrm{de}$ & $0.8389 \pm 0.387 \mathrm{~d}$ & $1.006 \pm 0.224 \mathrm{ijkl}$ & 2 & & \\
\hline $000 \pm 0.0 \mathrm{e}$ & $0.7100 \pm 0.000 \mathrm{~d}$ & $0.862 \pm 0.129 \mathrm{klm}$ & 0 & & \\
\hline $0.00 \pm 0.0 \mathrm{e}$ & $0.7100 \pm 0.000 \mathrm{~d}$ & $1.546 \pm 0.994 \mathrm{cdef}$ & 0.1 & \multirow{3}{*}{ Root } & \\
\hline $0.9222 \pm 0.328 \mathrm{bcde}$ & $1.228 \pm 0.788 b c$ & $2.149 \pm 0.866 \mathrm{a}$ & 0.5 & & \\
\hline $0.7744 \pm 0.129 \mathrm{de}$ & $1.312 \pm 0.938 \mathrm{~b}$ & $1.268 \pm 0.446 \mathrm{efghi}$ & 2 & & \\
\hline $1.071 \pm 0.607 \mathrm{abcd}$ & $1.031 \pm 0.534 \mathrm{bcd}$ & $0.746 \pm 0.045 \mathrm{~lm}$ & 0 & \multirow{4}{*}{ Leaf } & \multirow{12}{*}{ Glucose } \\
\hline $0.00 \pm 0.0 \mathrm{e}$ & $0.7100 \pm 0.000 \mathrm{~d}$ & $1.017 \pm 0.271 \mathrm{ijkl}$ & 0.1 & & \\
\hline $0.8289 \pm 0.251 \mathrm{cde}$ & $0.9422 \pm 0.483 \mathrm{bcd}$ & $1.511 \pm 0.525 \mathrm{def}$ & 0.5 & & \\
\hline $0.9956 \pm 0.445$ abcde & $1.776 \pm 1.627 \mathrm{a}$ & $1.508 \pm 0.547 \mathrm{def}$ & 2 & & \\
\hline $0.9078 \pm 0.404 \mathrm{bcde}$ & $0.9167 \pm 0.427 \mathrm{~cd}$ & $0.710 \pm 0.002 \mathrm{~m}$ & 0 & \multirow{4}{*}{ Shoot } & \\
\hline $0.00 \pm 0.0 \mathrm{e}$ & $0.7100 \pm 0.000 \mathrm{~d}$ & $1.086 \pm 0.205 \mathrm{ijk}$ & 0.1 & & \\
\hline $0.8744 \pm 0.344$ bcde & $0.9489 \pm 0.551 \mathrm{bcd}$ & $1.546 \pm 0.497 \mathrm{cdef}$ & 0.5 & & \\
\hline $0.8144 \pm 0.210 \mathrm{de}$ & $0.9733 \pm 0.431 \mathrm{bcd}$ & $1.481 \pm 0.593 \mathrm{defg}$ & 2 & & \\
\hline 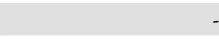 & - & $1.171 \pm 0.526 \mathrm{hij}$ & 0 & \multirow{4}{*}{ Root } & \\
\hline - & - & $1.258 \pm 0.356$ fghi & 0.1 & & \\
\hline - & - & $1.564 \pm 0.171 \mathrm{bcde}$ & 0.5 & & \\
\hline- & - & $1.453 \pm 0.061 \mathrm{efgh}$ & 2 & & \\
\hline
\end{tabular}

\section{Suspension culture and artemisinin content}

The friable white calli were used to establish homogenous cell suspension culture (Fig. 11). It has to be mentioned that the calli obtained from the medium containing glucose were not suitable to prepare suspension culture as they were compact in texture and had a low growth rate. For growth analysis, samples were taken on the first day after subculturing at $72 \mathrm{~h}$ intervals until the $30^{\text {th }}$ day of subculturing and cell dry weight was used for generating a growth curve.

The maximum growth rate of suspension culture was achieved in the MS liquid medium containing NAA and BAP in the same concentrations and sucrose or glucose as the carbon source (Fig. 9). This is in agreement with Keng et al. (2007) results, that the best proliferation of $A$. annua cell suspension was obtained in the equal concentrations of NAA and BAP $(0.25 \mathrm{mg} / \mathrm{l})$. In the current experiment, the highest proliferation rate was obtained in the MS medium containing $0.5 \mathrm{mg} / \mathrm{L} \mathrm{NAA}, 0.5 \mathrm{mg} / \mathrm{L} \mathrm{BAP}$ and $30 \mathrm{~g} / \mathrm{L}$ glucose (Fig. 9).

The best cell suspension culture in terms of producing homogenized suspension and the highest proliferation rate was selected for further experiments. The calli obtained from $0.5 \mathrm{mg} / \mathrm{L} \mathrm{NAA}, 0.5 \mathrm{mg} / \mathrm{L} \mathrm{BAP}$ and $30 \mathrm{~g} / \mathrm{L}$ sucrose were transferred into the liquid medium of the same composition except that sucrose was replaced with glucose (Fig. 12). In the same condition, glucose was recommended in comparison with sucrose to increase the artemisinin production by cell suspension culture. In this regard, Wang and Weathers (2007) reported that artemisinin accumulation was 2 -fold higher in glucose-fed suspension culture compared to the sucrose treated. Weathers et al. (2004) mentioned that the induced artemisinin in hairy root culture of $A$. annua increased by using glucose instead of sucrose. Arsenault et al. (2010) introduced fructose as an important simple sugar that inhibited artemisinin production and glucose for the stimulation of artemisinin, as it does not decompose to fructose.
According to the the results of the TTC test, cells were in the exponential phase for 14 days. For 2 days they remained in the stationary phase, then after the $16^{\text {th }}$ day, cells entered the death phase. The results of the TTC test demonstrated that the maximum formozan absorption was at the $16^{\text {th }}$ day, and it gradually decreased (Fig. 14).

The results of artemisinin measurement during the 34 days indicated that artemisinin naturally can be produced with at least $0.03 \mathrm{mg} / \mathrm{g}$ (w.dt) at the first day and the maximum of $0.31 \mathrm{mg} / \mathrm{g}$ (w.dt) on the $16^{\text {th }}$ day in the cell culture of $A$. annua (Fig. 13).

\section{Shoot induction}

Different responses were observed with explants one month after culture in different treatments. The highest number of shoots was observed in the presence of $2 \mathrm{mg} / \mathrm{l}$ BAP, $0.1 \mathrm{mg} / \mathrm{l} \mathrm{NAA}$ and $30 \mathrm{~g} / \mathrm{L}$ sucrose (Table 10).

Leaf explants produced the same number of shoots as shoot explants (Table 4, Fig. 7). A higher number of shoots was induced by high and low levels of BAP and NAA, respectively. Le (2001) also reported that the presence of BAP in the medium caused axiliary shoot promotion. The interaction between different concentrations of NAA and $\mathrm{BAP}$ revealed that the mediums containing $2 \mathrm{mg} / \mathrm{L} \mathrm{BAP}$, $0.1 \mathrm{mg} / \mathrm{L} \mathrm{NAA}+0.5 \mathrm{mg} / \mathrm{L} \mathrm{BAP}, 0.1 \mathrm{mg} / \mathrm{L} \mathrm{NAA}+2 \mathrm{mg} / \mathrm{L}$ $\mathrm{BAP}$ and $0.5 \mathrm{mg} / \mathrm{L} \mathrm{NAA}+0.5 \mathrm{mg} / \mathrm{L} \mathrm{BAP}$ induced more shoots per explant (Table 2). According to Zia et al. (2007) in $A$. absinthium the highest number of shoots was obtained using $0.5 \mathrm{mg} / \mathrm{l} \mathrm{BAP}+0.1 \mathrm{mg} / \mathrm{l} \mathrm{NAA}$.

For shoot regeneration, BAP $(0.5$ and $2 \mathrm{mg} / \mathrm{L})$ was used in combination with $30 \mathrm{~g} / \mathrm{L}$ sucrose or glucose. The maximum number of shoot was obtained (Table 5) from 2 $\mathrm{mg} / \mathrm{l} \mathrm{BAP}+$ sucrose $(1.746 \pm 0.9)$. On one hand, increasing $\mathrm{BAP}$ (as a shoot induction hormone) concentration from 0.5 to $2 \mathrm{mg} / \mathrm{L}$ did not improve shoot proliferation rate when glucose was used. In other words, the amount of 0.5 $\mathrm{mg} / \mathrm{L} \mathrm{BAP}$ induced more number of shoots $(1.468 \pm 0.5)$ than $2 \mathrm{mg} / \mathrm{L} \mathrm{BAP}(1.27 \pm 0.3)$, while glucose was used as a 

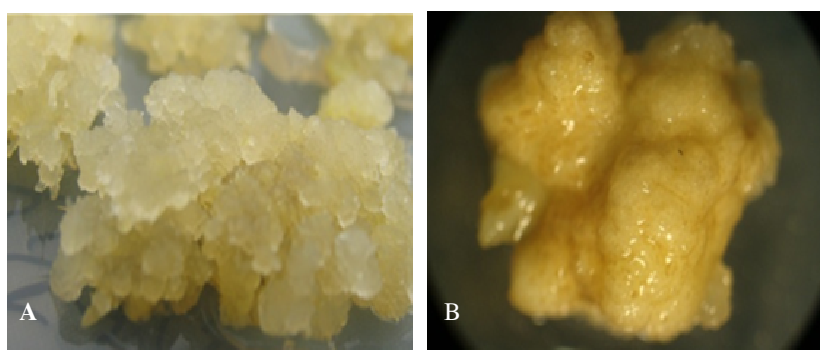

Fig. 1. Morphologically different calli induced by different combinations of growth regulators and carbon sources; A) friable callus in the medium containing $2 \mathrm{mg} / \mathrm{L} \mathrm{BAP}+0.1 \mathrm{mg} / \mathrm{L} \mathrm{NAA}$; B) compact callus in the medium containing $0.5 \mathrm{mg} / \mathrm{LBAP}$
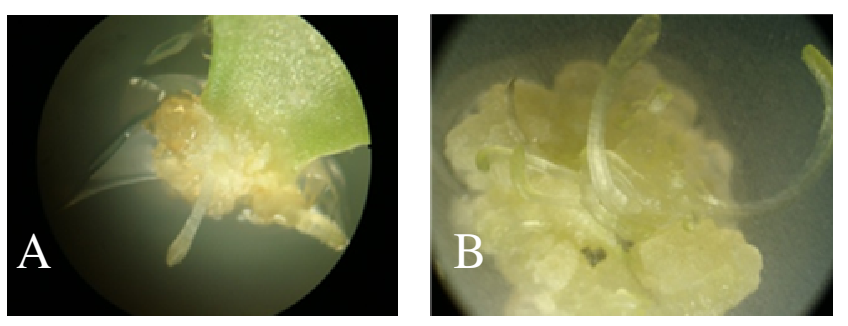

Fig. 3. Shoot induction in the medium containing $0.1 \mathrm{mg} / \mathrm{L} \mathrm{NAA}+2$ $\mathrm{mg} / \mathrm{LBAP}$ from leaf explants after 2 weeks (A) and after one month (B)
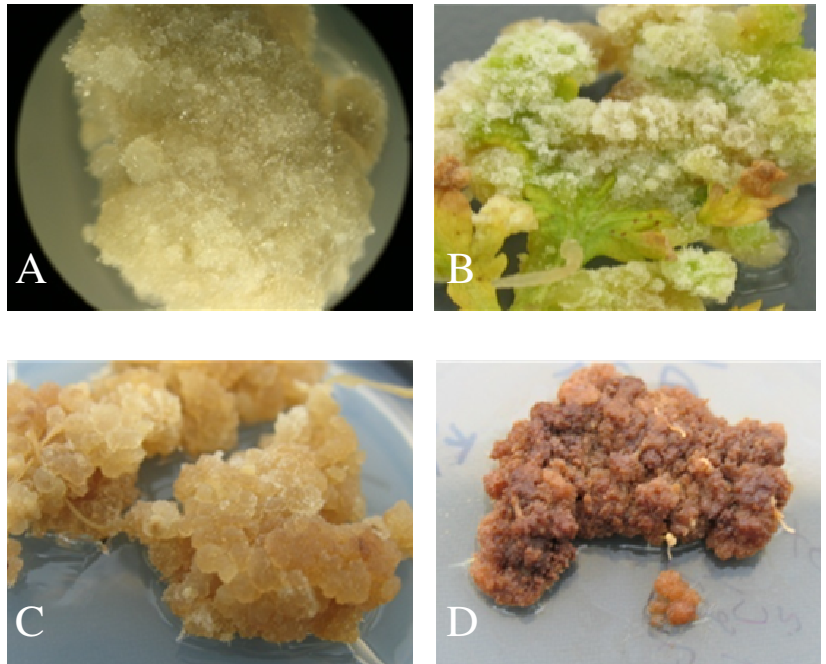

Fig. 2. Different colors of calli initiated in the MS medium containing different concentrations of NAA and BAP and carbon sources; A: white calli (leaf explants, $0.5 \mathrm{mg} / \mathrm{LNAA}+0.5 \mathrm{mg} / \mathrm{LBAP}+$ sucrose); B: snow white calli (leaf explants, $2 \mathrm{mg} / \mathrm{L} \mathrm{NAA}+0.5 \mathrm{mg} / \mathrm{L} \mathrm{BAP}+$ glucose); C: light brown (leaf explants, $0.1 \mathrm{mg} / \mathrm{L} \mathrm{NAA}+0.5 \mathrm{MG} / \mathrm{l}$ $\mathrm{BAP}+$ sucrose); D: dark brown calli (root explants, $2 \mathrm{mg} / \mathrm{L} \mathrm{BAP}+2$ $\mathrm{mg} / \mathrm{LNAA}+$ sucrose)
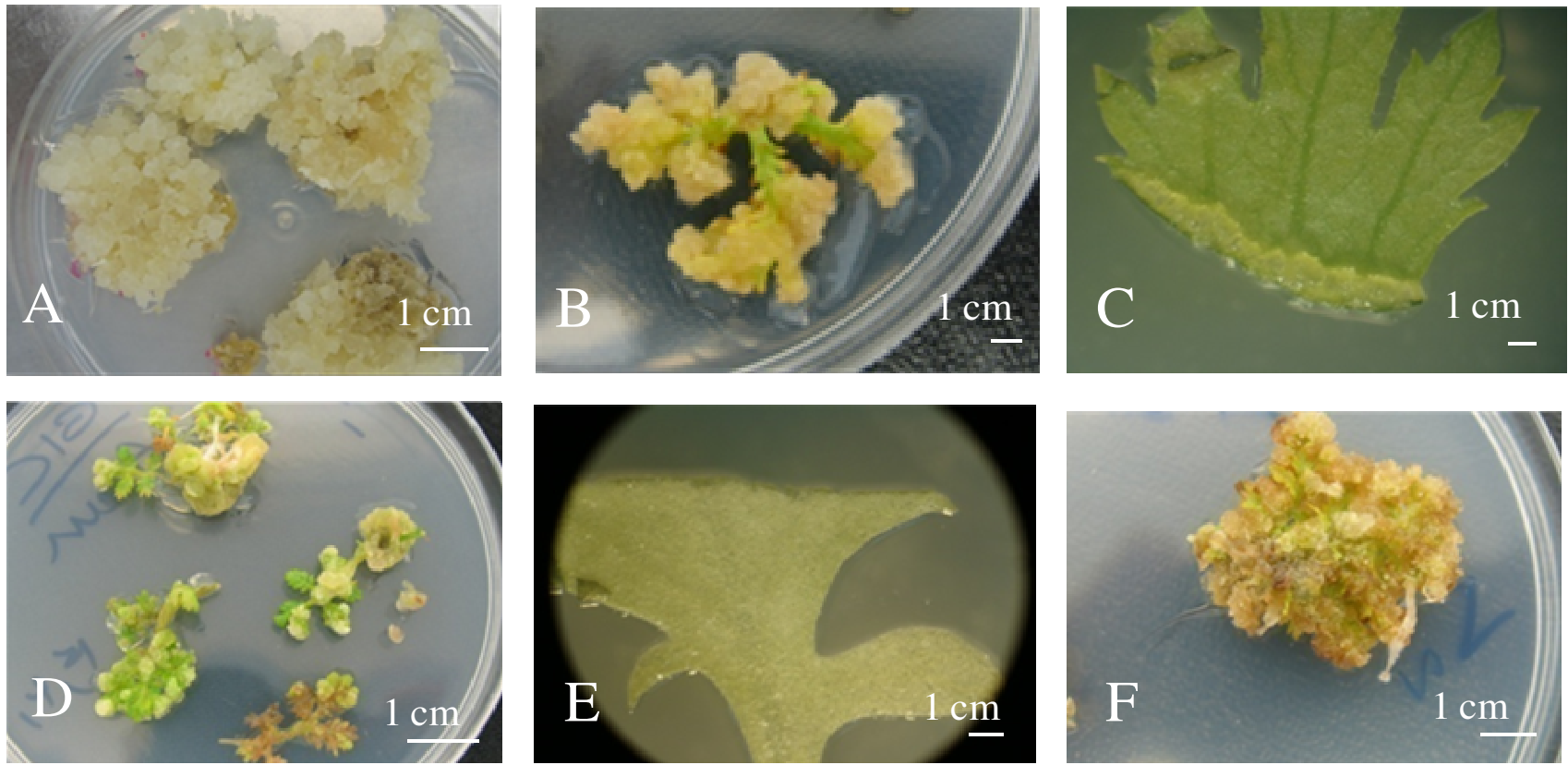

Fig. 4. Callus formation process. Callus formation began on the $7^{\text {th }}$ day of subcultering on wound areas and in medium containing sucrose (A) and glucose (D); The growth of callus on $15^{\text {th }}$ day in medium containing sucrose (B) and glucose (E); Grown callus in $30^{\text {th }}$ day in medium containing sucrose $(\mathrm{C})$ and glucose $(\mathrm{F})$
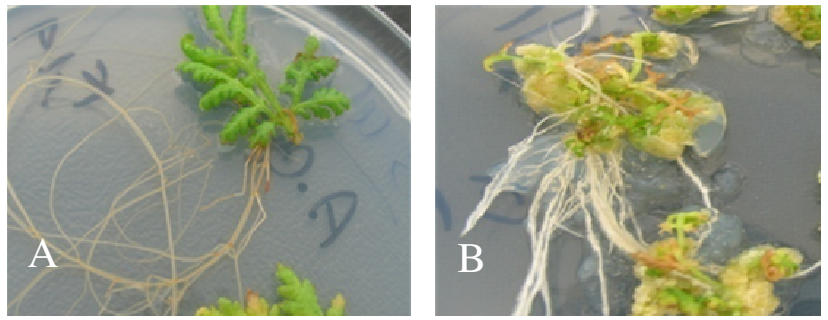

Fig. 5. The longest induced roots at $0.5 \mathrm{mg} / \mathrm{lNAA}+$ sucrose (A), and 2 $\mathrm{mg} / \mathrm{lNAA}+$ sucrose (B) with leaf explants of $A$. annua
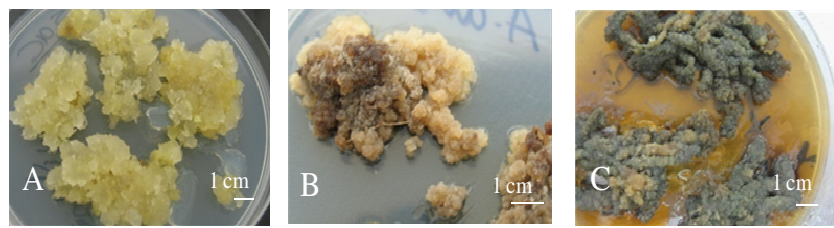

Fig. 6. The colour changing of calli from root explants

(A) The white calli in $7^{\text {th }}$ day; (B) Browning of calli because of the phenol released in medium culture due to the delay in subculturing at $14^{\text {th }}$ day and $30^{\text {th }}$ day $(\mathrm{C})$ 


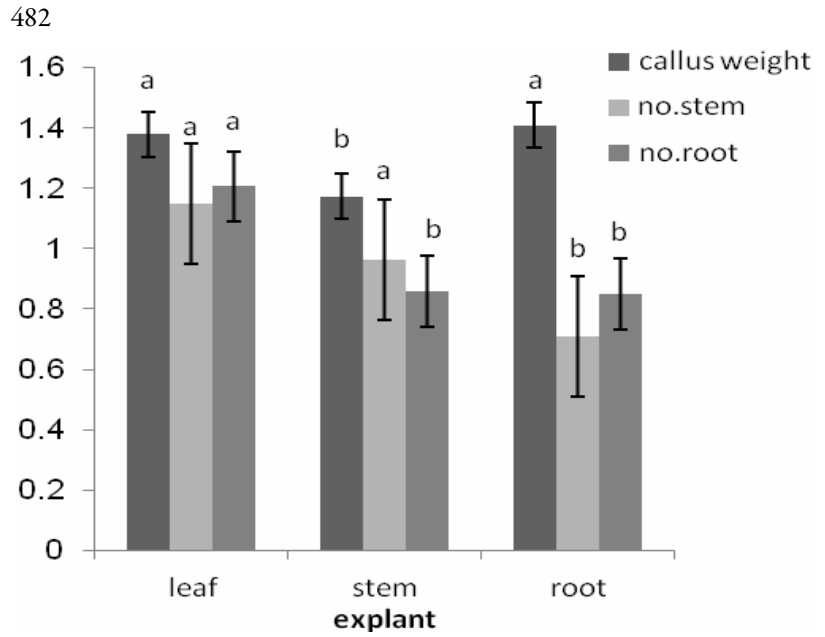

Fig. 7. The effect of explant on callus, shoot and root induction of $A$. annua; Duncan's multiple range test at $0.1 \%$ probability

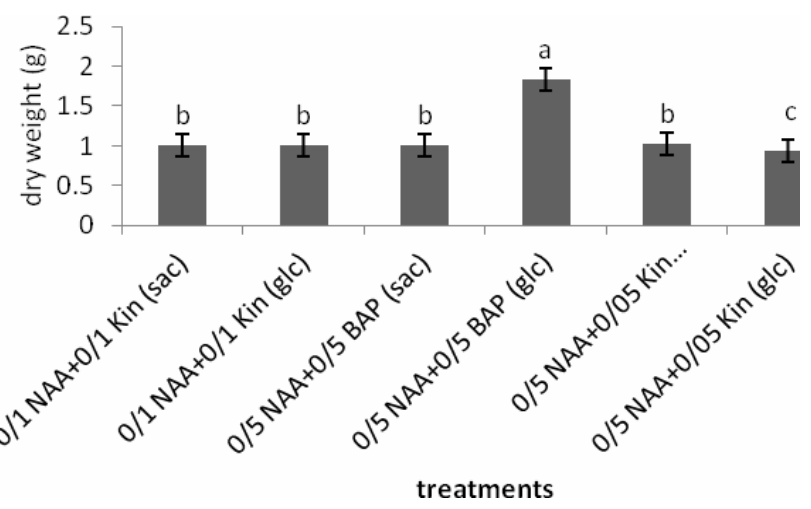

Fig. 9. Different concentrations of growth regulators with sucrose and glucose for the establishment of suspension culture of $A$. annua
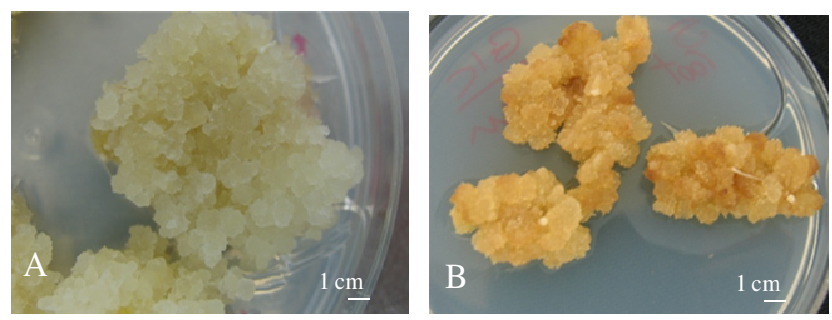

Fig. 11. The light brown calli obtained from $0.1 \mathrm{mg} / \mathrm{L}$ NAA and 2 $\mathrm{mg} / \mathrm{L}$ BAP (A); white calli obtained from $0.5 \mathrm{mg} / \mathrm{L} \mathrm{NAA}$ and 0.5 $\mathrm{mg} / \mathrm{LBAP}(\mathrm{B})$ which was selected for suspension culture

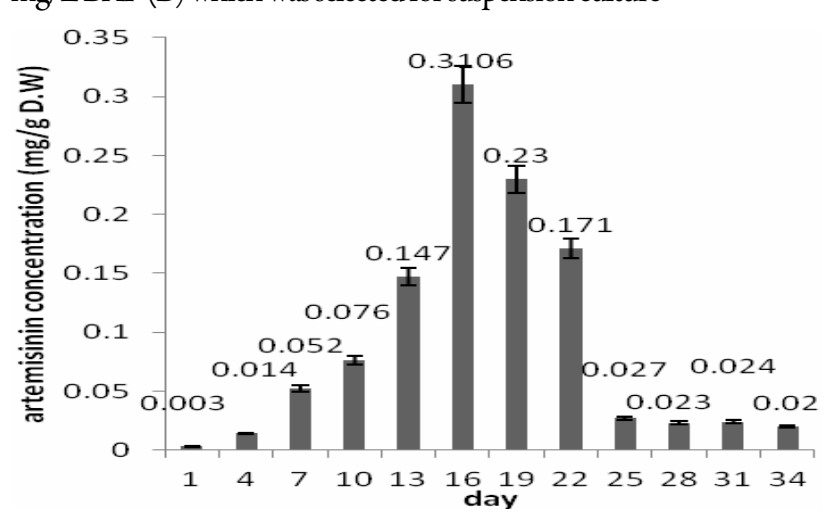

Fig. 13. The artemisinin production by $A$. annua cells during a month culture

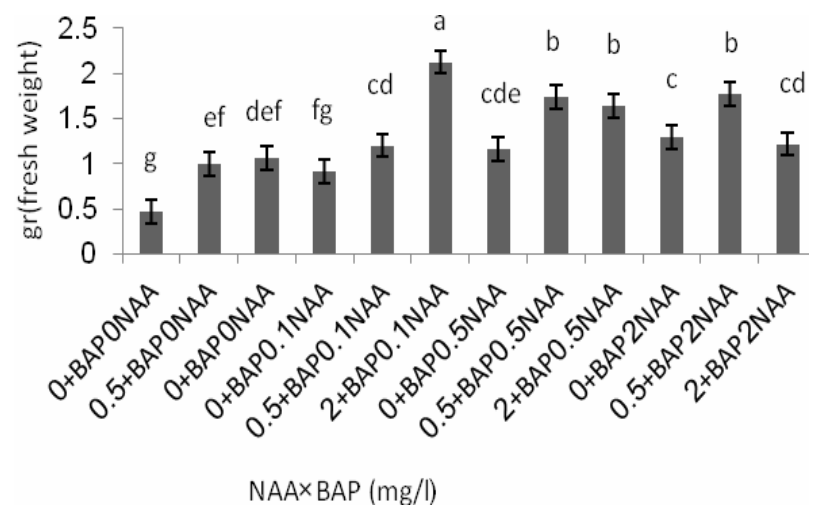

Fig. 8. The effect of interaction of NAA and BAP on fresh weight of callus; Duncan's multiple range test at $0.1 \%$ probability level

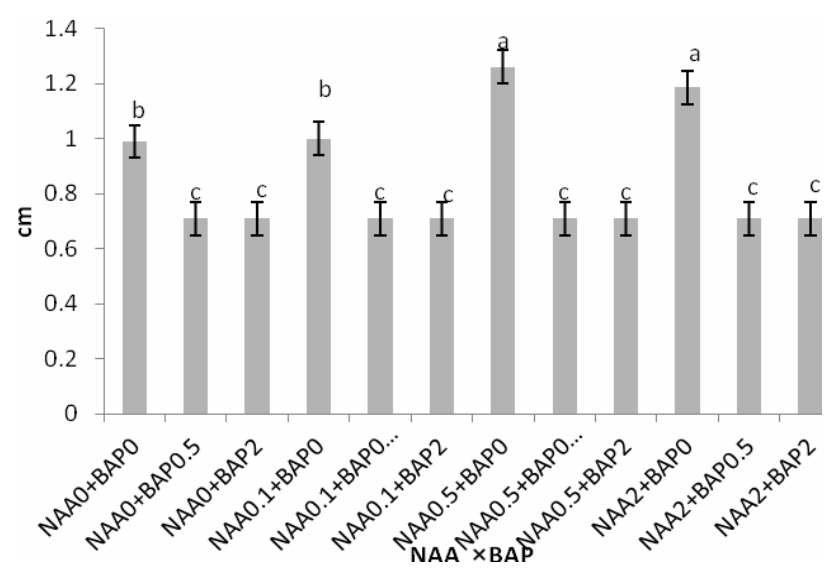

Fig. 10. The effect of interaction of NAA and BAP on root growth; Duncan's multiple range test at $0.1 \%$ probability level
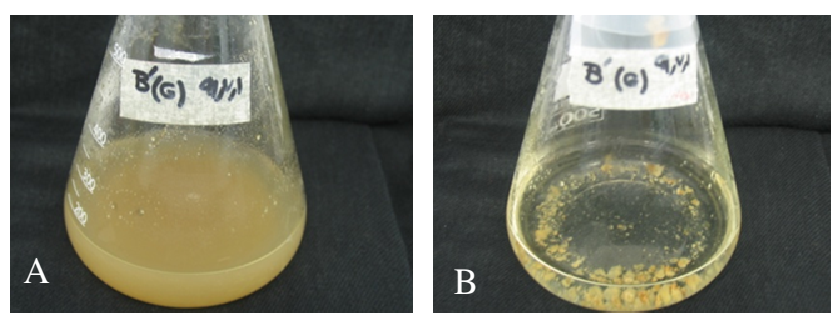

Fig. 12. Suspension culture of $A$. annua at first day (A), after a month (B), in medium containing $0.5 \mathrm{mg} / \mathrm{L} \mathrm{NAA}$ and BAP

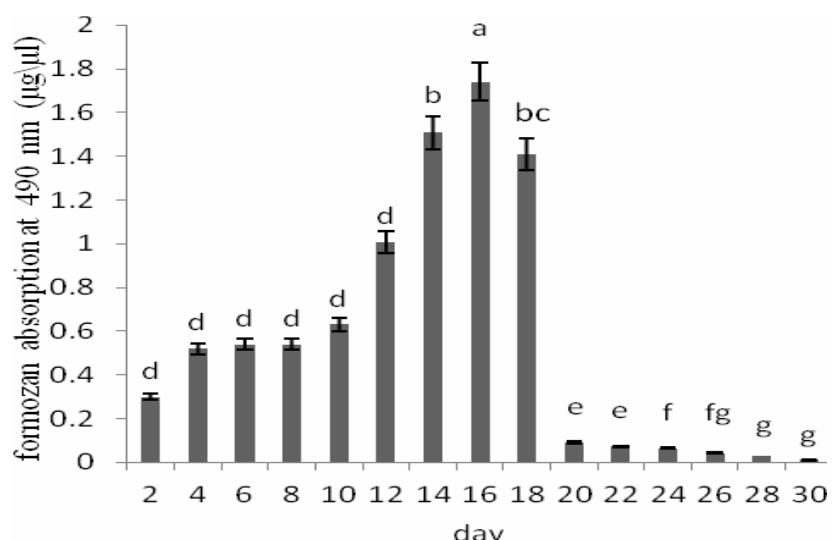

Fig. 14. The formozan absorption by spectrophotometer within 30 days 


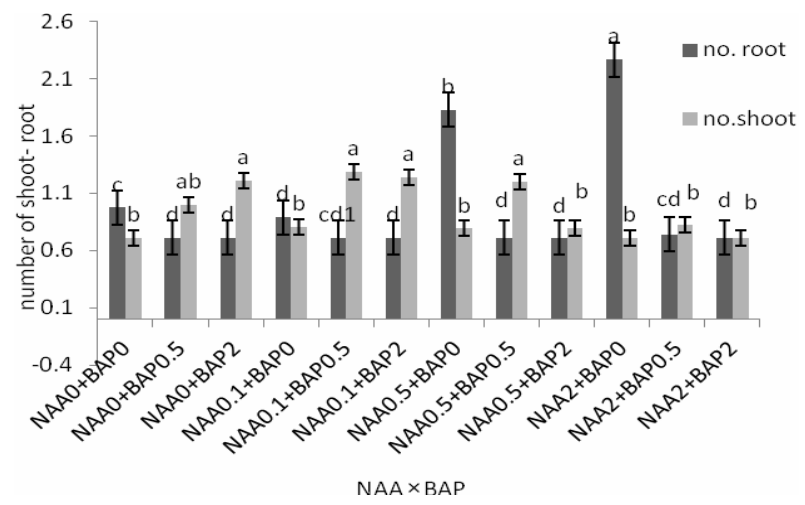

Fig. 15. The effect of combinations of NAA and BAP on shoot and root induction; Duncan's multiple range test at $0.1 \%$ probability level

carbon source (Table 5). On the other hand, there was no significant difference in shoot induction using various concentrations of BAP (Table 3). Therefore, it can be deduced that carbon has an indirect effect on BAP for shoot generation. Briefly, sucrose may enhance and glucose may lessen the effect of BAP.

The effect of different explants and concentrations of BAP on shoot induction showed that the maximum number of shoots was induced in 0.5 or $2 \mathrm{mg} / \mathrm{L} \mathrm{BAP}$ with leaf and then in $0.5 \mathrm{mg} / \mathrm{L} \mathrm{BAP}$ with shoot explants (Table 7). Less or higher amounts of BAP may be required for shoot and leaf explants based on the internal growth regulators each one possesses.

In investigation of different concentrations of NAA, no significant difference was observed between $0,0.1$ and 0.5 $\mathrm{mg} / \mathrm{L}$ NAA, but the shoot regeneration decreased when 2 mg/L NAA was used (Table 8). No difference was observed in the interaction of NAA and carbon source for shoot induction. The interaction between explants and NAA indicated that leaf explants in the medium containing 0 and $0.1 \mathrm{mg} / \mathrm{L} \mathrm{NAA}(1.26 \pm 0.8$ and $1.527 \pm 0.9$ respectively) induced more shoots (Table 6). It showed that leaf explants had a better response than shoot explants for shoot induction in the presence of NAA.

\section{Shoot length}

The higher concentration of BAP alone induced a greater number of shoots, but decreased the shoot length (Table 3). There were no differences between the interaction of different concentrations of NAA and BAP on shoot length (Table 2). The interaction between NAA, BAP and carbon source showed that the best result was obtained from 0.5 $\mathrm{mg} / \mathrm{L}$ NAA and BAP with sucrose (Table10). Thus, the same concentration of NAA and BAP in the medium containing sucrose seemed better for the elongation of regenerated shoots.

Longer shoots were induced by sucrose. However, there was no difference between sucrose and glucose on shoot elongation in combination with BAP (Table 5).

In surveying the effects of explant type, BAP concentration and carbon source, it was found that the medium supplemented with $0.5 \mathrm{mg} / \mathrm{l} \mathrm{BAP}$ and $30 \mathrm{~g} / \mathrm{L}$ sucrose induced more shoots than leaf explants (Table 11).

Investigation of the effect of NAA on shoot elongation using different explants (Table 6) showed that leaf explants at $0.1 \mathrm{mg} / \mathrm{l} \mathrm{NAA}(0.973 \mathrm{~cm} \pm 0.272)$ and then 0.1 and 0.5 $\mathrm{mg} / \mathrm{L}$ NAA with shoot explants induced longer shoots $(0.899 \mathrm{~cm} \pm 0.3$ and $0.921 \mathrm{~cm} \pm 0.39$, respectively). In addition, investigation on the effect of carbon source with NAA (Table 9) showed that $0.1 \mathrm{mg} / \mathrm{L}$ NAA with sucrose or glucose and $0.5 \mathrm{mg} / \mathrm{L} \mathrm{NAA}$ with sucrose induced the highest shoot length $(0.849 \mathrm{~cm} \pm 0.2,0.873 \mathrm{~cm} \pm 0.3$ and $0.91 \mathrm{~cm} \pm$ 0.3 , respectively).

Leaf and shoot explants were the same in shoot height induction (Table 4) and interaction of BAP and explants (Table 7) showed that $0.5 \mathrm{mg} / \mathrm{L} \mathrm{BAP}$ with leaf explants induced higher shoots $(1.009 \mathrm{~cm} \pm 0.3)$. It can be deduced that although leaf and shoot explants were the same for the elongation of regenerated shoots, they had different reactions to BAP.

Longer shoots were induced in the media containing either $0.5 \mathrm{mg} / \mathrm{l} \mathrm{NAA}$ plus $0.5 \mathrm{mg} / \mathrm{l} \mathrm{BAP}$ with $30 \mathrm{~g} / \mathrm{L}$ sucrose, using leaf explants $(1.493 \mathrm{~cm} \pm 0.342)$ or $0.5 \mathrm{mg} / \mathrm{l} \mathrm{NAA}$, with $30 \mathrm{~g} / \mathrm{L}$ sucrose with shoot explants $(0.697 \mathrm{~cm} \pm 0.930)$.

\section{Root induction}

A great number of roots were induced from leaf explants (1.206 \pm 1.073$)$ compared to other explants (Table 4, Fig. 7). Application of $30 \mathrm{~g} / \mathrm{L}$ sucrose with 0.5 or $2 \mathrm{mg} / \mathrm{L} \mathrm{NAA}$ or 30 $\mathrm{g} / \mathrm{L}$ glucose with $2 \mathrm{mg} / \mathrm{L}$ NAA (Table 9) led to the induction of more roots $(1.298 \pm 0.039,1.323 \pm 0.60$ and $1.153 \pm$ 0.041 , respectively). Interestingly, glucose in combination with the higher concentration of NAA $(2 \mathrm{mg} / \mathrm{L})$ induced roots, but generally sucrose had a better effect on root induction.

Investigation of NAA alone showed that the maximum number of roots was obtained from $2 \mathrm{mg} / \mathrm{l} \mathrm{NAA}$ (Table 8). Moreover, investigation of NAA and carbon source determined that NAA at 0.5 and $2 \mathrm{mg} / \mathrm{L}$ with sucrose and at $2 \mathrm{mg} / \mathrm{L}$ with glucose induced more shoots (Table 9). It can be inferred that the presence of carbon can influence the effect of NAA. Sucrose amplified its effect while glucose had no significant effect. The mechanism of carbon effect on plant growth regulators is unknown yet and needs further molecular investigations. The maximum number of roots was produced on the medium supplemented with 0.5 or $2 \mathrm{mg} / \mathrm{l}$ of NAA without BAP (Table 2). Wang and Weathers (2007) reported that BAP inhibited root induction when it was used in combination with sucrose and glucose. They also mentioned that in $A$. annua glucose induced artemisinin production, but inhibited root proliferation.

By investigating the interaction effect of NAA and explants (Table 6), the highest number of roots was obtained in $2 \mathrm{mg} / \mathrm{L}$ NAA with leaf explants. Root explants did not form adventitious roots in 0 or $0.1 \mathrm{mg} / \mathrm{L} \mathrm{NAA}$. Interaction effect of BAP $\times$ NAA $\times$ explants $\times$ carbon source showed that more roots were induced in the media containing 0.5 or $2 \mathrm{mg} / \mathrm{L} \mathrm{NAA}$ and $30 \mathrm{~g} / \mathrm{L}$ sucrose (without BAP) with leaf explants ( $4.033 \pm 0.449$ and $3.597 \pm 0.904$, respectively). Le (2001) induced a large number of roots using $0.5 \mathrm{mg} / \mathrm{L} \mathrm{IBA}$ in $A$. annua.

Roots were induced from leaf explants on all concentrations of NAA (without BAP) plus $30 \mathrm{~g} / \mathrm{L}$ sucrose. However, when glucose was used, only on the medium containing 0.5 and $2 \mathrm{mg} / \mathrm{l}$ NAA plus $30 \mathrm{~g} / \mathrm{L}$ glucose $(1.672 \pm 0.5$ and $1.818 \pm 0.6$ respectively), roots were induced (Table 12). 
484

Generally, roots were induced from shoots on a BAP-free medium in both surveying of interaction between BAP and sucrose (Table 5) or explants (Table 7). Besides, by the investigation of carbon, explants and BAP demonstrated that sucrose with leaf explants without BAP had the best result $(2.474 \pm 0.5)$ for root induction (Table 11).

More root induction was observed by increasing NAA concentration, but in contrast to the initial prediction, the maximum number of roots was obtained with leaf explants (not from the roots).

\section{Root length}

The medium containing $0.1 \mathrm{mg} / \mathrm{lNAA}$ and $30 \mathrm{~g} / \mathrm{L}$ sucrose, using leaf explants $(2.232 \pm 0.748)$ was proposed to achieve longer roots, based on the results obtained from the interaction of the four factors. Without considering the explants, the medium supplemented with $0.5 \mathrm{mg} / \mathrm{L} \mathrm{NAA}$ and sucrose was the best medium to obtain longer roots (Table 10). It showed that internal ingredients in explants is important, since by considering explants, lower concentration of NAAwas needed $(0.1 \mathrm{mg} / \mathrm{L}$ for leaf against $0.5 \mathrm{mg} / \mathrm{L}$ for root explants) to obtain more roots.

In the interaction between NAA and $\mathrm{BAP}$, the longest roots were obtained in 0.5 or $2 \mathrm{mg} / \mathrm{l} \mathrm{NAA}$, without BAP (Fig. 10, Table 2).

The study on the interaction of carbon source and explants showed that the maximum and minimum lengths of the induced roots were obtained with leaf and root explants on a medium supplemented with sucrose and glucose, respectively. The longest roots $(0.976 \mathrm{~cm} \pm 0.558)$ were emerged from leaf explants (Table 4).

By increasing NAA concentration, more roots were induced, but there was no difference between roots length (Table 8). Moreover, the interaction between carbon and NAA showed that the medium containing $0.5 \mathrm{mg} / \mathrm{L}$ NAA and sucrose induced more roots (Table 9). It seems that sucrose has a positive effect on the function of NAA for both root induction and growth.

The presence of BAP had a negative effect on the growth of regenerated roots (Table 3). The interaction between BAP and carbon source (Table 5) revealed that the medium supplemented with sucrose, without BAP, and then glucose, without BAP induced the highest number of roots $(1.99 \mathrm{~cm} \pm 0.6$ and $1.08 \mathrm{~cm}$ $\pm 0.4)$ respectively. Therefore, it indicated that carbon source could not suppress the negative effect of BAP on growth of roots.

\section{Conclusions}

The findings of this study revealed that depending on the investigating factors (explants such as leaf, shoot and root, carbon source (sucrose and glucose) and different concentrations of NAA and BAP), studied singly and in combination with others, results differed. Most of the induced calli were friable and suitable to produce suspension culture, but it strongly depended on the time of subculturing, as the rate of callogenesis was proportional to the age of explants. Explants derived from young seedlings produced the fastest growing calli. In this study it was found that leaves and roots were the best explant types for callus induction. Glucose was recommended in comparison with sucrose to increase the artemisinin production by cell suspension culture. It seems that sucrose has a positive effect on the function of NAA for both root induction and growth.

\section{References}

Arsenault PR, Vail DR, Wobbe KK, Weathers PJ (2010). Effect of sugars on artemisinin production in Artemisia annua L.: transcription and metabolite measurements. Molecules 15:23022318.

Aslam N, Zia M, Chaudhary MF (2006). Callogenesis and direct organogenesis of Artemisia scoparia. Pakistan Journal of Biological Science 9:1783-1783.

Borzabad RK, Sudarshana MS, Niranjan MH (2010a). In vitro plant regeneration from stem derived callus of Artemisia vulgaris L.. Report an Opinion 2(12):121-125.

Borzabad RK, Sudarshana MS, Niranjan MH (2010b). In vitro plant regeneration from leaf explants of Artemisia vulgaris L-a medicinal herb. Modern Applied Science 4(9):130.

De Ridder S, Van der Kooy F, Verpoorte R (2008). Artemisia annua as a self-reliant treatment for malaria in developing countries. Journal of Ethnopharmacology 120:302-314.

Deus-Neumann B, Zenk M (1984). Instability of indole alkaloid production in Catharanthus roseus cell suspension cultures. Planta Medica 50:427-431.

Eckstein-Ludwig U, Webb R, Van Goethem I, East J, Lee A, Kimura M, O'Neill P, Bray P, Ward S, Krishna S (2003). Artemisinins target the SERCA of Plasmodium falciparum. Nature 424:957-961.

Ganesan C, Paulsamy S (2011a). Standardized protocol for the in vitro culture of Artemisia annua L.- A medicinal plant at high altitudes of Nilgiris, the Western Ghats. Journal of Research in Biology 1:173178.

Ganesan CM, Paulsamy S (2011b). Mass propagation of a threatened medicinal plant, Artemisia nilagirica (CB Clarke) Pampan inhabiting high hills of Nilgiris, the Western Ghats. Indian Journal of Fundamental and Applied Life Sciences 1(3):1421.

Keng CL, Singaram N, Lim BP (2007). Production of artemisinin from cell suspension culture of Artemisia annua L. In: Proceedings Asia Pacific Conference on Plant Tissue and Agribiotechnology (APaCPA) Vol 17 pp 21.

Kim N-C, Kim J-G, Kim S, Lim H, Hahm T (1992). Production of secondary metabolites by tissue culture of Artemisia annua $\mathrm{L}$. Journal of the Korean Agricultural Chemical Society 35.

Klayman DL (1985). Qinghaosu (artemisinin): an antimalarial drug from China. Science 228(4703):1049-1055.

Le CL (2001). In vitro propagation of Artemisia annua L. as a meaningful tool for the selection and domestication of high artemisinin yielding clones. Quality enhancement of plant production through tissue culture. Working group 2.

Lei C, Ma D, Pu G, Qiu X, Du Z, Wang H, Li G, Ye H, Liu B (2011). Foliar application of chitosan activates artemisinin biosynthesis in Artemisia annua L. Industrial Crops and Products 33:176-182.

Murch SJ, Krishna Raj S, Saxena PK (2000). Phyto-pharmaceuticals: massproduction, standardization, and conservation. Herbal Medicine 4(2):39-43.

Nin S, Morosi E, SchiffS, Bennici A (1996). Callus cultures of Artemisia absinthium L: initiation, growth optimization and organogenesis. Plant Cell, Tissue and Organ Culture 45:67-72. 
Paniego N, Giulietti A (1994). Artemisia annua L.: dedifferentiated and differentiated cultures. Plant Cell, Tissue and Organ Culture 36:163-168.

Poobathy R, Hesam NAA, Julkifle AL, Subramaniam S (2012). Vitrification and histological analyses of protocorm-like bodies of Vanda Kaseem's Delight orchid. Australian Journal of Crop Science 6(2):219-224.

Smith TC, Weathers PJ, Cheetham RD (1997). Effects of gibberellic acid on hairy root cultures of Artemisia annua: growth and artemisinin production. In Vitro Cellular \& Developmental Biology-Plant 33:75-79.

Snow RW, Guerra CA, Noor AM, Myint HY, Hay SI (2005). The global distribution of clinical episodes of Plasmodium falciparum malaria. Nature 434:214-217.

Sujatha G, Kumari BR (2007). Effect of phytohormones on micropropagation of Artemisia vulgaris L. Acta Physiologiae Plantarum 29:189-195.

Utzinger J, Xiao S-H, Tanner M, Keiser J (2007). Artemisinins for schistosomiasis and beyond. Current Opinion in Investigational Drugs 8:105-116.
Van Agtmael MA, Eggelte TA, van Boxtel CJ (1999). Artemisinin drugs in the treatment of malaria: from medicinal herb to registered medication. Trends in Pharmacological Sciences 20:199-205.

Wang Y, Weathers P (2007). Sugars proportionately affect artemisinin production. Plant Cell Reports 26:1073-1081.

Weathers P, Dejesus-Gonzalez L, Kim Y, Souret F, Towler M (2004). Alteration of biomass and artemisinin production in Artemisia annua hairy roots by media sterilization method and sugars. Plant Cell Reports 23:414-418.

Yin H, Kjaer A, Fretté XC, Du Y, Christensen LP, Jensen M, Grevsen K (2012). Chitosan oligosaccharide and salicylic acid up-regulate gene expression differently in relation to the biosynthesis of artemisinin in Artemisia annua L. Process Biochemistry 47(11):1559-1562.

Zia M, Mannan A, Chaudhary MF (2007). Effect of growth regulators and amino acids on artemisinin production in the callus of Artemisia absinthium. Pakistan Journal of Botany 39(3):799-805.

Zia M, Rehman R, Chaudhary MF (2007). Hormonal regulation for callogenesis and organgenesis of Artemisia absinthium L. African Journal of Biotechnology 6(16):1874-1878. 